\title{
Criança não é Manga, não Amadurece: Conceito de Maturação na Teoria Histórico-Cultural
}

\author{
Children Are Not Mangos, Do Not Get Ripe: \\ Concept Of Maturation In The Historical-Cultural Theory \\ Un Niño No Es Un Mango, No Madura: \\ Concepto De Maduración En La Teoría Histórico Cultural
}

Flávia da Silva Ferreira Asbahr

Universidade Estadual Paulista Júlio de Júlio de Mesquita

Carolina Picchetti Nascimento

Universidade de São Paulo
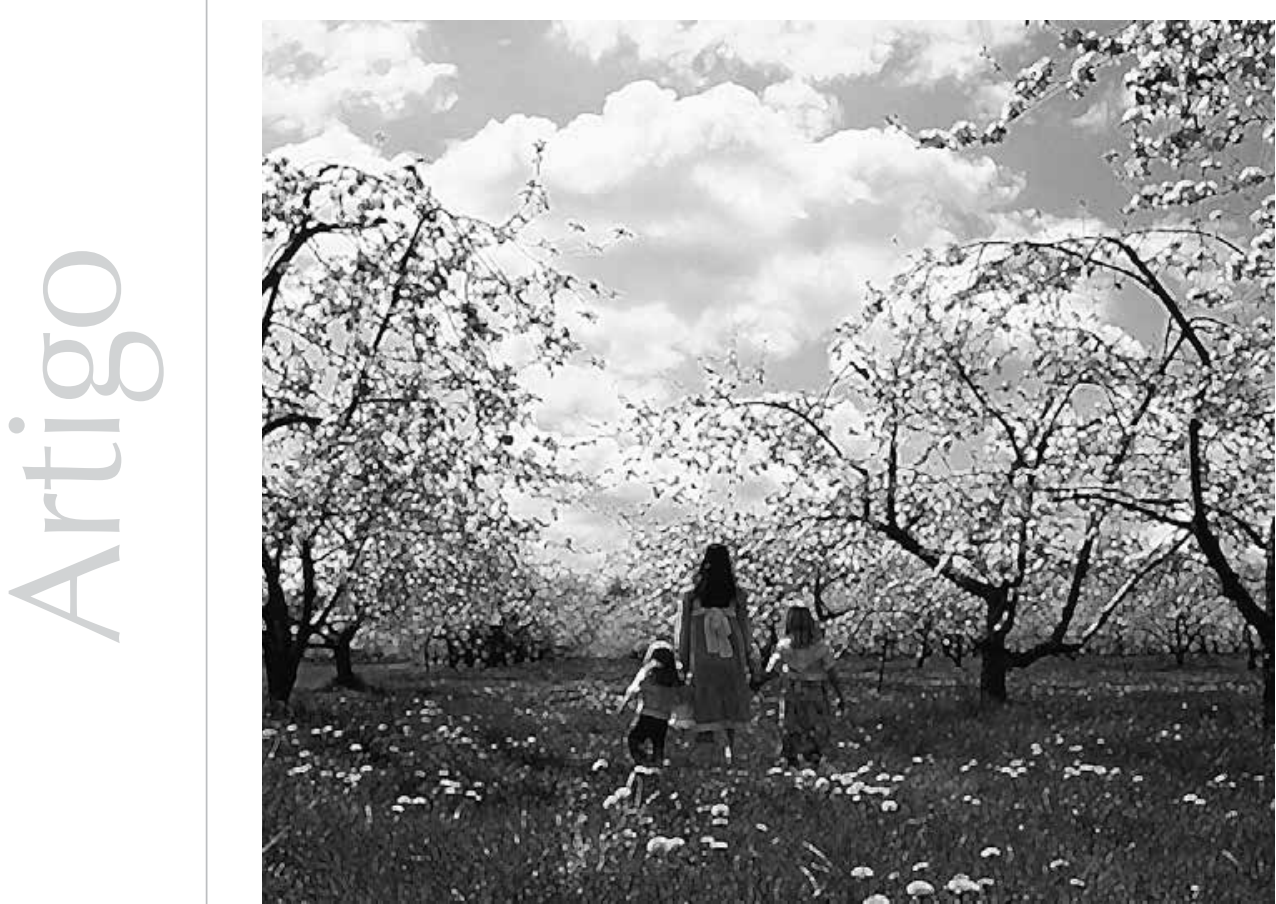
Resumo :A ideia da maturação do desenvolvimento fundamenta, de modo bastante recorrente, as explicações sobre o fracasso escolar: o aluno não aprende porque é imaturo, e resta à escola esperar que ele amadureça. Quando se diz que uma criança não está madura, em comparação ao desenvolvimento já alcançado por um adulto, foca-se apenas nas diferenças quantitativas entre eles e se esquece que essas novas qualidades do adulto não surgiram nele pela maturação, mas sim, pelo permanente processo de apropriação da cultura humana. Dessa forma, a referida ideia de maturação do desenvolvimento expressa uma profunda biologização do ser humano, reduzindo ao aparato biológico do indivíduo a explicação de problemas sociais e educacionais. O objetivo deste ensaio é analisar as relações entre a maturação e o desenvolvimento, apontando os limites das explicações biologicistas dos fenômenos humanos e as possibilidades da explicação elaborada pela teoria histórico-cultural para a organização do trabalho pedagógico. Essa concepção reconfigura o papel da maturação no processo de aprendizagem e confere à educação escolar um lugar central no desenvolvimento das funções psicológicas superiores. Assim, não cabe à escola esperar que a criança amadureça, ao contrário, é seu dever criar condições para que a maturação se efetive.

Palavras-chave: Desenvolvimento humano. Aprendizagem. Desenvolvimento infantil. Teoria históricocultural.

\begin{abstract}
The idea of "mature development" is based, frequently, on explanations of school failure: the student does not learn because he is immature and the school has to wait until he gets "mature." When one says that a child is not mature compared to the development already attained by an adult, one focuses only the quantitative differences between them and forgets that these new qualities of the adult did not arise by the maturation, but by the permanent appropriation process of the human culture. Thus, this idea of "maturity of development" expresses a deep biologization of the human being, reducing social and educational problems explanation to the biological apparatus of the individual. The purpose of this essay is to analyze the relationship between maturation and development, pointing out the limits of biologists' explanations of human phenomena and the possibilities of explanation formulated by the historical-cultural theory to the organization of pedagogical work. This concept gives a new configuration to the role of maturation in the learning process and gives the school education a central role in the development of higher psychological functions. Thus, the school does not have to wait for the child's maturation. Rather, it is its duty to create conditions for his/her maturation to become effective.
\end{abstract}

Keywords: Human development. Learning. Childhood development. Cultural-historical theory.

Resumen: La idea de la "maduración del desarrollo" fundamenta, de modo bastante recurrente, las explicaciones sobre el fracaso escolar: el alumno no aprende porque es inmaduro, y le resta a la escuela esperar que él "madure". Cuando se dice que un niño no está maduro, en comparación al desarrollo ya alcanzado por un adulto, se focaliza apenas en las diferencias cuantitativas entre ellos y se olvida que esas nuevas cualidades del adulto no surgieron en él por la maduración, sino, por el permanente proceso de apropiación de la cultura humana. De esa forma, la referida idea de "maduración del desarrollo" expresa una profunda biologización del ser humano, reduciendo al aparato biológico del individuo la explicación de problemas sociales y educacionales. El objetivo de este ensayo es analizar las relaciones entre la maduración y el desarrollo, apuntando los límites de las explicaciones biologicistas de los fenómenos humanos y las posibilidades de la explicación elaborada por la teoría histórico cultural para la organización del trabajo pedagógico. Esa concepción reconfigura el papel de la maduración en el proceso de aprendizaje y le otorga a la educación escolar un lugar central en el desarrollo de las funciones psicológicas superiores. Así, no le cabe a la escuela esperar que el niño madure, al contrario, es su deber crear condiciones para que la madurez se efective.

Palabras clave: Desarrollo humano. Aprendizaje. Desarrollo infantil. Teoría histórico-cultural.

Em nossas atuações como psicóloga escolar e como professora de educação física em escolas públicas, uma questão sempre nos incomoda: os discursos cristalizados e fetichizados sobre a prática pedagógica e sobre as relações de ensino e aprendizagem que dela se depreendem. Um desses discursos, usados para explicar porque determinadas crianças não aprendem, refere-se à maturação do desenvolvimento e da aprendizagem. É comum escutarmos professores, psicólogos e pesquisadores dizendo que o aluno tal não aprende porque é imaturo ou não tem maturidade. Nessa perspectiva, as hipóteses para o fracasso escolar de determinados alunos poderiam ser expressas em frases como: idade mental inferior à cronológica, limítrofe, infantil, imaturo, bobinho. 
Em uma das escolas públicas em que trabalhamos, uma professora de $4 \underline{\underline{a}}$ série dizia aos seus alunos que a classe era como uma grande mangueira, tinha algumas mangas já madurinhas, prontas para aprender, mas também tinha mangas verdinhas, imaturas, que precisavam ser regadas até ficarem prontas para a aprendizagem. Enquanto isso, esperar seria o melhor remédio, seria a estratégia pedagógica mais adequada.

Na mesma perspectiva, temos escutado tais discursos vindos de psicólogos, que, ao buscarem explicar as dificuldades de aprendizagem das crianças que atendem, utilizam frequentemente a maturação (ou melhor, sua falta) como causa dessas dificuldades. Olhar os traços do desenho de uma criança, muitas vezes, já é suficiente para dizer que ela é imatura, logo, não aprende.

As concepções acima mencionadas aparecem para nós como portadoras de uma verdade quase inquestionável: as crianças que não aprendem determinados conteúdos (particularmente aqueles que são ensinados na escola) não desenvolveram determinadas qualidades psicológicas. Assim, um aluno que não é capaz de manter sua atenção ao realizar uma tarefa relativamente prolongada não desenvolveu, ainda, a sua atenção voluntária. Entretanto, essa "verdade quase inquestionável" é uma verdade apenas no nível da aparência. Trata-se de uma conclusão a partir da observação da realidade que nos é apresentada imediatamente. Avalia-se que o estudante não consegue aprender determinado conteúdo e sabe-se que tal conteúdo se relaciona a uma determinada função psíquica, logo, conclui-se que essa função não amadureceu e que essa seria a causa de seu fracasso escolar.

A relação entre aprendizagem e desenvolvimento das funções psíquicas captadas em sua imediaticidade, tal qual exposta no exemplo anterior - oculta a essência contida nessa relação ou a verdadeira explicação sobre os processos de ensino, aprendizagem e desenvolvimento.
O objetivo deste ensaio é analisar as relações entre a maturação e o desenvolvimento, apontando os limites das explicações biologicistas dos fenômenos humanos e as possibilidades da explicação elaborada pela teoria histórico-cultural de Vigotski e seus colaboradores para a organização do trabalho escolar. Ressalta-se que outros autores elaboraram sínteses das concepções sobre desenvolvimento e aprendizagem advindos da teoria histórico-cultural, como, por exemplo, Facci (2004), Teixeira (2003), Chaiklin (2011) e Pasqualini (2009), entre outros. No entanto, o enfoque deste artigo está no conceito de maturação e em como tal conceito tem permeado a prática pedagógica.

Primeiramente, apresentaremos a análise crítica realizada por Vigotski às teorias do desenvolvimento de sua época, especialmente ao conceito de maturação. Em um segundo momento, exporemos o conceito de maturação do desenvolvimento humano presente na teoria histórico-cultural.

\section{Teorias sobre o desenvolvimento e o conceito de maturação}

A explicação sobre os processos de aprendizagem e desenvolvimento baseadas no conceito de maturação expressa a aparência dessa relação e, ao mesmo tempo, uma profunda biologização desses processos. A biologização das explicações sobre o fracasso escolar, incorporada de forma hegemônica no discurso do senso comum, está presente em diferentes teorias psicológicas sobre o desenvolvimento humano, teorias essas que, em última instância, servem de fundamento para o próprio discurso do senso comum. Ao dizer que determinado aluno é infantil ou imaturo, o professor remete-se a teorias do desenvolvimento infantil estudadas durante seu curso de formação que retratam o desenvolvimento humano como algo maturacional, linear, determinístico. E, mesmo sem ter estudado profundamente tais teorias do desenvolvimento, são elas que embasam seu trabalho. Sendo assim, apenas 
cabe ao professor esperar que seu aluno amadureça.

Entendemos que a relação entre desenvolvimento e aprendizagem é uma questão central para a prática pedagógica, sobretudo porque nos remete às questões relacionadas a o que ensinar (os conteúdos), como ensinar (o modo de organizar o ensino) e porque ensinar (a finalidade da educação escolar).

Uma das importâncias em se estudar o processo de desenvolvimento humano está justamente em sua relação com a aprendizagem. As teorias sobre o desenvolvimento humano, através de suas explicações sobre o que se desenvolve no homem e como se desenvolve, delimitam as possibilidades da aprendizagem, ou seja, avaliam se ela pode ou não interferir nesse desenvolvimento e-sobretudo - como ela pode nele interferir.

Nessa perspectiva, o desenvolvimento refere-se, de maneira geral, às mudanças que ocorrem ao longo do ciclo de vida de um indivíduo. O estudo do desenvolvimento humano está voltado, entre outras coisas, para explicar os fatores que influenciam ou que determinam as mudanças no comportamento do indivíduo ao longo do tempo.

Nesse sentido, e ainda que não explicitamente, as teorias pedagógicas e as práticas educativas que se dão na concreticidade das salas de aula estão fundamentadas por uma concepção de desenvolvimento humano, isto é, têm por referência alguma explicação sobre as possibilidades de vir a ser do homem. É nessa medida que podemos afirmar que as teorias sobre o desenvolvimento humano possuem uma implicação prática na formação do próprio homem.

Vigotski é um dos autores que analisa as concepções de desenvolvimento e aprendizagem subjacentes a algumas teorias psicológicas de sua época e suas possíveis implicações educacionais. O autor divide as teorias que explicam a relação entre desenvolvimento e aprendizagem em três categorias fundamentais - a concepção inatista, a concepção empirista/ambientalista e a concepção dualista -, reconhece que, nessas concepções, há uma compreensão maturacionista do desenvolvimento e critica tais abordagens:

Segundo essas teorias, a aprendizagem é um processo puramente exterior, paralelo, de certa forma, ao processo de desenvolvimento da criança, mas que não participa ativamente neste e não o modifica absolutamente: a aprendizagem utiliza os resultados do desenvolvimento, em vez de se adiantar ao seu curso e de mudar a sua direção (Vigotski, 1988, p.103)

Esse autor não só analisou tais teorias como também as criticou, principalmente no que se refere às suas implicações pedagógicas. Segundo tais teorias, a escola só pode fazer seu trabalho depois que a criança atingir determinado nível de maturação:

O desenvolvimento deve atingir uma determinada etapa, com a conseqüente maturação de determinadas funções, antes de a escola fazer a criança adquirir determinados conhecimentos e hábitos. $\mathrm{O}$ curso do desenvolvimento precede sempre o da aprendizagem. A aprendizagem segue o desenvolvimento. Semelhante concepção não permite sequer colocar o problema do papel que podem desempenhar, no desenvolvimento, a aprendizagem e a maturação das funções ativadas no curso da aprendizagem. O desenvolvimento e a maturação dessas funções representam um pressuposto, e não um resultado da aprendizagem (Vigotski, 1988, p. 104)

Vamos a cada uma dessas concepções e a como analisam o papel da maturação no desenvolvimento infantil.

Até determinado momento da história da ciência, particularmente com relação às teorias que procuravam explicar o desenvolvimento humano, a teoria inatista ou pré-formista aparecia como a visão hegemônica. Essa concepção, atualmente, está relativamente ausente das explicações sobre o desenvolvimento humano, contudo, 
seu estudo ainda se mostra importante. Tal importância se justifica tanto pelo seu valor histórico (como um estágio das teorias sobre o desenvolvimento humano, e que influenciou as teorias subsequentes) quanto pela persistência de parte de suas ideias como modos de ação para as análises. Ainda que uma teoria tenha desaparecido da ciência, de modo que não haja mais uma defesa aberta de suas ideias, não raro, elas se mantêm presentes na forma de "hábitos de pensamentos" (Vigotski, 1995), que condicionam as práticas educacionais e de pesquisa.

Para os adeptos da teoria inatista, o desenvolvimento humano caracteriza-se, fundamentalmente, pelo seu potencial intrínseco (hereditário), com pouca ou nenhuma influência do meio. Os processos de crescimento físico e maturacional - em última análise, o organismo - determinam incondicionalmente o processo de desenvolvimento. Assim, o estado de desenvolvimento da criança de dez anos de idade seria produto direto do seu estado maturacional, isto é, de suas forças internas.

Nota-se, nessa concepção, que a explicação dada para o desenvolvimento humano não guarda diferença substancial com o tipo de explicação dada para o processo de desenvolvimento do animal; não há qualquer singularidade no processo de desenvolvimento do homem comparativamente ao do animal. Nesse sentido, o desenvolvimento humano resumir-se-ia a um processo de amadurecimento meramente biológico, movido pelas forças e pelas transformações internas do organismo.

Não existindo mais uma defesa aberta das ideias dessa teoria (ou ao menos não hegemonicamente), resta sabermos em que essa concepção influencia ainda hoje nosso pensamento ou nossos "hábitos de pensamento", conforme Vigotski (1995).

A primeira delas, um tanto quanto influente nas práticas educacionais, é a manutenção da crença de um certo desenvolvimento natural da criança, da crença da existência de uma força intrínseca à criança (processos maturacionais), que saberia ao certo para onde conduzi-la no seu desenvolvimento e na qual não deveríamos interferir. Makarenko (1980), fazendo crítica a esse tipo de pensamento nos educadores - o do espontaneísmo do desenvolvimento infantil -, cita uma interessante metáfora, retrucando as crenças de alguns teóricos de que a criança poderia desenvolver-se muito bem sem a interferência dos adultos. Segundo o autor, em condições de natureza pura, crescem apenas "ervas daninhas" (p. 147).

A segunda forma de influência do pensamento inatista nos dias de hoje relaciona-se à prática de investigação científica e referese à redução do desenvolvimento humano a um processo puramente quantitativo. $\mathrm{O}$ indivíduo é reduzido, na teoria inatista, a um ser biológico, cujas características já estão dadas desde o nascimento, restando apenas que elas sejam desabrochadas. Dessa forma, a descoberta do processo de desenvolvimento especificamente humano torna-se impossível, assim como a captação e a explicação de todas as mudanças e transformações verificadas na conduta da criança em uma sociedade histórica e culturalmente produzida. Desse modo, o desenvolvimento, para essa teoria, comanda a aprendizagem, cabendo a esta última apenas aproveitar aquilo que o desenvolvimento já lhe ofereceu. Nessa visão, o estudante reúne ou não as condições ou aptidões para aprender, de acordo com as características hereditárias que possui.

Como negação da teoria inatista, a teoria empirista/ambientalista do desenvolvimento humano procurou deslocar todas as explicações dadas para a formação do ser humano (que residiam no organismo) para o meio. Para essa teoria, todo o conhecimento dos seres humanos provém de sua experiência no meio físico e social ao qual ele está inserido, meio esse que provoca mudanças no comportamento do indivíduo. Esse processo caracterizaria o desenvolvimento, para essa teoria. 
Carvalho (1999), em seu artigo De Psicologismos, Pedagogismos e Educação, critica a realização de transposições diretas das teorias psicológicas para a prática educativa.
Trata-se, assim, de uma inversão, dentro da mesma concepção determinista do desenvolvimento humano; os ambientalistas negam o determinismo biológico dado pela teoria inatista para afirmarem o determinismo ambiental no desenvolvimento do homem. $\mathrm{E}$, justamente por ser uma teoria determinista do desenvolvimento, consideramos que seja, também, uma teoria reducionista, incapaz, portanto, de explicar em sua totalidade o desenvolvimento especificamente humano.

De acordo com essa concepção, a educação era vista como mero processo de transmissão de conteúdos, transmitidos pelo professor e recebido pelos alunos, que teriam seu comportamento moldado de acordo com esse processo, ou seja, o meio determinaria inteiramente o desenvolvimento do homem; os seres humanos seriam uma cópia das condições externas.

Apesar de as teorias inatistas e ambientalistas do desenvolvimento humano guardarem muitas diferenças entre si, apresentam um ponto em comum que parece aproximá-las mais do que as suas diferenças podem afastálas: trata-se de suas concepções deterministas e a-históricas do desenvolvimento humano.

O terceiro grupo teórico busca conciliar as concepções apresentadas anteriormente, fazendo com que coexistam. Trata-se da concepção dualista de desenvolvimento, que considera a existência, por um lado, do processo de maturação que depende do desenvolvimento neurológico, e, de outro, da aprendizagem considerada em si mesma como processo de desenvolvimento. Vigotski resume as novidades dessa teoria em três pontos: conciliam-se dois pontos de vista antes considerados contraditórios, considera-se a questão da interdependência de dois processos fundamentais, amplia-se o papel da aprendizagem no desenvolvimento infantil. O desenvolvimento, porém, continua expressando um âmbito mais amplo do que a aprendizagem: "A relação entre ambos os processos pode representar-se esquematicamente por meio de dois círculos concêntricos; o pequeno representa o processo de aprendizagem, e o maior, o do desenvolvimento, que se estende para além da aprendizagem" (Vigotski, 1988, p.109).

Vigotski procura uma nova solução para o problema da relação desenvolvimento e aprendizagem que supere as concepções maturacionistas e ambientalistas presentes nas teorias analisadas. Uma psicologia verdadeiramente histórica e que supere esses determinismos (biológicos e ambientalistas) nasce juntamente à tentativa de elaborar uma psicologia fundamentada no materialismo histórico-dialético: a teoria histórico-cultural.

\section{A concepção de desenvolvimento na teoria histórico-cultural. Ou, por que esperar a maturação não nos permite esperar que a criança se desenvolva?}

Carvalho (1999), em seu artigo De Psicologismos, Pedagogismos e Educação, critica a realização de transposições diretas das teorias psicológicas para a prática educativa. Será, então, que não estaríamos equivocados ao tentar explicitar uma outra teoria psicológica e buscar nela fundamentos para nossa prática pedagógica? A essa pergunta, respondemos que não.

Antes de mais nada, a teoria históricocultural não é uma metodologia nova ou um conjunto de técnicas para auxiliar a prática pedagógica, mas é, fundamentalmente, uma forma de entender o homem naquilo que ele é e naquilo que ele pode vir a ser. Tratase, em essência, da elaboração das questões psicológicas sobre o que se desenvolve no homem e como se desenvolve, a partir da explicitação e da defesa de uma certa concepção de mundo e de homem: ambos essencialmente históricos.

Mais do que isso, a teoria histórico-cultural tem as questões educacionais como base e finalidade de suas investigações, posto que, 
Vigotski explicita e desenvolve em seus trabalhos a tese já bastante difundida atualmente de que "o único bom ensino é o que se adianta ao desenvolvimento" (1988, p. 114). para ela, o desenvolvimento especificamente humano não ocorre sem o ensino, seja ele intencional ou não. Vigotski explicita e desenvolve em seus trabalhos a tese já bastante difundida atualmente de que "o único bom ensino é o que se adianta ao desenvolvimento" (1988, p. 114).

Entretanto, essa explicação psicológica embora possa e deva constituir fundamento da prática educativa, não pode ser tomada como ponto final desta última. Queremos dizer com isso que essa fundamentação não retira a necessidade de estudarmos os problemas concretos da educação escolar e de cada disciplina em particular, embora seja capaz de criar as bases para tal estudo.

O primeiro aspecto a ser realçado da concepção de desenvolvimento da teoria histórico-cultural é a compreensão de que a criança não é um adulto em miniatura. Há uma constituição infantil específica, tanto física como psicológica, que diferencia adultos e crianças não apenas quantitativamente, mas principalmente qualitativamente. Além disso, o desenvolvimento infantil não é linear, causado por acumulações sucessivas. Há metamorfoses, revoluções radicais no processo de desenvolvimento pelas quais passa a criança que irão garantir sua passagem de ser biológico para ser cultural. Essas metamorfoses não são produzidas biologicamente, pelo curso natural do desenvolvimento, mas pela inserção da criança no mundo histórico-cultural:

Uma vez integrada num ambiente
adequado, a criança sofre rápidas
transformações e alterações: esse é um
processo surpreendentemente rápido,
porque o ambiente sociocultural pré-
existente estimula na criança as formas
necessárias de adaptação, há muito tempo
criadas nos adultos que a rodeiam (Vigotski
\& Luria, 1993, p.180)

Assim, entender o que seja o desenvolvimento infantil na perspectiva da teoria históricocultural implica assumir que: a) existe uma linha histórico-cultural do desenvolvimento
(Vigotski, 1995) que se diferencia de sua linha biológica, b) para desenvolver-se culturalmente, é preciso apropriar-se dos significados historicamente produzidos nas atividades humanas (Leontiev, 1983).

Ao postular a existência de uma linha biológica e de uma linha histórica no processo de desenvolvimento humano, Vigotski procura ressaltar os aspectos essenciais que fizeram e fazem o homem constituir um ser cultural, o que nos indica a possibilidade de intervenções conscientes no processo de formação de cada sujeito. Segundo o autor, as duas linhas entrelaçam-se dialeticamente no processo de desenvolvimento, formando uma unidade no processo de humanização, ou seja, o aspecto biológico é o ponto de partida do desenvolvimento humano, mas altera-se no decorrer do processo de apropriação da cultura pelo sujeito, na medida em que:

Tendo dominado os processos que determinam sua própria natureza, o homem que hoje está lutando contra velhice e doenças ascenderá, indubitavelmente, a um nível mais elevado e transformará sua própria organização biológica. Mas essa é a fonte do maior paradoxo histórico do desenvolvimento contido nessa transformação biológica do tipo humano, que é alcançada principalmente por meio da ciência, da educação social e da racionalização dos modos de vida. A alteração biológica do homem não representa uma condição prévia para esses fatores, mas, ao invés disso, é um resultado da liberação social do homem (Vigotski, 1930)

A linha biológica do desenvolvimento humano caracteriza-se, sobretudo, por uma relação direta do homem com o mundo, por comportamentos espontâneos ou imediatos, dos quais ele não tem consciência e, assim, não pode controlar plenamente. $\mathrm{O}$ segundo tipo de desenvolvimento caracteriza-se pelo surgimento de novas formas de conduta condutas mediadas -, fruto das conquistas culturais que o homem foi alcançando em suas atividades. Com essas formas culturais de conduta, o homem pôde criar seus órgãos 
A cultura origina formas especiais de conduta, modifica a atividade das funções psíquicas, edifica novos níveis nos sistemas de comportamento humano em desenvolvimento (...) $\mathrm{No}$

processo de desenvolvimento histórico, o

homem social modifica os modos e os procedimentos de sua conduta, transforma suas inclinações naturais e

funções, elabora e cria novas formas de comportamento, especificamente culturais (Vigotski, 1995, p.34) artificiais (instrumentos e signos) e formar uma existência consciente ou uma existência para-si (Heller, 1991).

A cultura origina formas especiais de conduta, modifica a atividade das funções psíquicas, edifica novos níveis nos sistemas de comportamento humano em desenvolvimento (...) No processo de desenvolvimento histórico, o homem social modifica os modos e os procedimentos de sua conduta, transforma suas inclinações naturais e funções, elabora e cria novas formas de comportamento, especificamente culturais (Vigotski, 1995, p.34)

O esforço em se explicitar as especificidades dessas duas linhas de desenvolvimento no homem, a biológica e a cultural, e mais amplamente o esforço em diferenciar os tipos de desenvolvimento do homem comparativamente ao dos animais, inclusive aqueles que nos são mais próximos (como os chipanzés), não se dá com a finalidade de simplesmente estabelecer uma hierarquia de superioridade e, nesse sentido, de desqualificação dos demais animais. Não se trata de um movimento antropocentrista; trata-se, sim, de compreender melhor as ações que permitem a cada homem se formar de acordo com as máximas possibilidades de desenvolvimento produzidas historicamente pela humanidade. E isso nos traz implicações fundamentais para as questões educativas.

Quando dizemos que a criança não está madura, nós a comparamos com um adulto e tomamos seu desenvolvimento como parâmetro. Nesse processo, esquecemonos das diferenças qualitativas entre o desenvolvimento infantil e o adulto, focandonos apenas nas diferenças quantitativas e esquecendo-nos que as novas qualidades do adulto não surgiram nele pela maturação, mas pelo permanente processo de apropriação da cultura humana.

Apropriar-se da cultura humana, do mundo de objetos e de relações humanas, não significa simplesmente o aprendizado de novos hábitos ou informações fornecidos pelo ambiente. A apropriação (ou a ação de apropriar-se do mundo) é um conceito que se aplica exclusivamente aos seres humanos por refletir um tipo específico ou particular de aprendizagem, presente apenas no homem.

O fato de os macacos poderem aprender uma porção de coisas, inclusive ações tidas como tipicamente humanas (como o uso de instrumentos), não significa que a diferença entre os processos de desenvolvimento de um e de outro inexista. Em primeiro lugar, aquilo que os macacos aprendem dificilmente, ou nunca, constitui uma atividade no sentido próprio dado por Leontiev (1983); tratase, mais bem, de ações isoladas, com seus significados, mas não de uma atividade estruturada ou de "inteiros modos de ação" (Heller, 2000). Em segundo lugar, por mais complexo que seja o que o macaco aprende, tal aprendizado, e mais do que isso, o não aprendizado desse elemento não implica uma diminuição da sua condição de ser macaco. O que ele aprende não constitui uma necessidade de vida, ao menos não do ponto de vista da espécie.

Um elefante quebra galhos das árvores e os utiliza para espantar as moscas. Porém, usar galhos para combater as moscas provavelmente não desempenhou nenhum papel considerável na história do desenvolvimento da espécie "o elefante". Os elefantes não se tornaram elefantes pela razão de que seus ancestrais mais ou menos tipo-elefante matavam moscas com galhos (Vigotski \& Luria, 1996, p. 88)

Um cão domesticado (e os animais domésticos em geral) experimenta um certo grau de socialização. Aprende determinados comportamentos que o meio social lhe impõe e cria para si determinadas necessidades também advindas desse meio (como, por exemplo, a necessidade de carinho de seu dono). Entretanto, tanto uma coisa quanto outra representam necessidades que não mudam substancialmente o seu comportamento de espécie e, em última análise, não representam necessidades da espécie como tal para que ela mesma se efetive. Trata-se, no fim, de uma necessidade 
que lhe é imposta pelo meio, de um comportamento que não afasta, e na verdade ratifica, o processo geral e universal de desenvolvimento dos animais: o processo de adaptação ao meio.

Para o homem, o processo se dá de forma diferente. "Toda a existência de um aborígene australiano depende de seu bumerangue, do mesmo modo que toda a existência da moderna Inglaterra depende de suas máquinas" (Vigotski \& Luria, 1996, p. 88). Não aprender determinadas coisas significa, concretamente, uma impossibilidade real de sua humanização, uma diminuição ou cerceamento de suas possibilidades de se formar como homem. As suas possibilidades de vir a ser homem efetivam-se de acordo com as possibilidades concretas/objetivas para se apropriar daquelas objetivações humanas historicamente formadas.

Para estabelecer a verdadeira diferença entre os instrumentos humanos e os instrumentos nos animais, devemos analisar, de acordo com Leontiev (1978), a atividade em que eles tomam parte. Para os animais, a sua atividade confunde-se sempre com o seu motivo biológico, e os instrumentos encerram, em si, uma possibilidade natural de realizar a sua atividade instintiva. Para o homem, por outro lado, o instrumento possibilita a criação e a apropriação de novas formas de sua atividade no mundo, com os outros e consigo mesmo.

(...) Na vara usada pelo macaco, já podemos ver o protótipo não só de um instrumento em geral mas de toda uma série de instrumentos diferenciados: pás, lanças, e assim por diante. Porém, mesmo no caso dos macacos que, no mundo animal, se encontram no ponto mais elevado quanto ao uso de instrumentos, esses instrumentos ainda não desempenham papel decisivo na luta pela sobrevivência. Na história do desenvolvimento do macaco, ainda não houve aquele salto para diante que constituiu o processo de transformação do macaco em homem, e isso, do ponto de vista que nos interessa, termina no fato de que os instrumentos de trabalho se tornam a base de adaptação à natureza. No processo de desenvolvimento do macaco, esse salto para diante teve início, mas não se completou. A fim de que se complete, é preciso que se desenvolva uma nova forma especial de adaptação à natureza, estranha aos macacos - ou seja, o trabalho (Vigotski \& Luria, 1996, p. 88)

Em outras palavras, a imitação e a utilização de instrumentos nos animais não cria neles um comportamento realmente novo (novos significados), mas apenas uma forma diferente de realizar o seu comportamento de espécie, tratando-se, assim, de um processo de adaptação. A imitação no ser humano, ou, mais amplamente, os processos de educação e de aprendizagem, os processos de objetivação e de apropriação da cultura são os processos universais de desenvolvimento de cada sujeito como indivíduo pertencente ao gênero humano, são os mecanismos universais para a produção de indivíduos cada vez mais ricos em necessidades humanas.

Assim, uma nova capacidade não surge no homem porque as capacidades orgânicas a ela vinculadas se aprimoram. Ao adquirir novas maneiras de ver e ouvir (e poderíamos também pensar em funções mais complexas, como ler, focar a atenção voluntariamente em algo e pensar teoricamente), isso não significa que tenham surgido nos homens refinamentos de suas capacidades sensoriais ou orgânicas, mas sim, que tenham surgido novas realidades sociais, novos objetos sociais, produzidos pelo próprio homem, que permitiram às capacidades orgânicas se transformarem e se tornarem capacidades propriamente humanas. É, portanto, nessa relação entre produção/apropriação de objetos culturais que o homem se formou como homem cultural, com capacidades e condutas culturais.

As aquisições do desenvolvimento histórico das aptidões humanas não são simplesmente dadas aos homens nos fenômenos objetivos da cultura material e espiritual que os encarnam, mas são aí apenas postas. Para se apropriar desses resultados, para fazer deles as suas aptidões, "os órgãos da 
sua individualidade", a criança, o ser humano, deve entrar em relação com os fenômenos do mundo circundante através de outros homens, isto é, num processo de comunicação com eles. Assim, a criança aprende a atividade adequada. Pela sua função, esse processo é, portanto, um processo de educação (Leontiev, 1978, p. 290, grifos do autor)

A argumentação de Leontiev parece deixar claro que não se trata, portanto, de uma simples posse dos objetos culturais, para que os mesmos resultem em uma mudança em nossas capacidades e condutas. Os objetos materiais e não materiais apropriados pelo homem no processo educativo contêm, apenas em termos de possibilidade, as formas de conduta especificamente humanas. Para que esses objetos possam, de fato, ser internalizados, o sujeito deve realizar uma atividade que reproduza as características essenciais da atividade humana em questão. Tal ato, por sua vez, só pode se dar mediante a colaboração de indivíduos mais experientes, posto que os significados sociais contidos nos objetos, nas atividades humanas, só podem ser revelados em uma atividade coletiva (social).

Ao estudar o desenvolvimento cultural do homem, a teoria histórico-cultural não nega a permanência e a importância das funções naturais (ou elementares) no desenvolvimento humano, mas afirma que não são essas funções que explicam a complexidade das funções especificamente humanas.

A tese fundamental, que conseguimos estabelecer ao analisar as funções psíquicas superiores, é o reconhecimento da base natural das formas culturais de comportamento. A cultura não cria nada, apenas modifica as atitudes naturais em concordância com os objetivos do homem (Vigotski, 1995, p. 152, tradução nossa)

A Psicologia, como ciência, precisa sair do cativeiro da Biologia e passar ao terreno da Psicologia histórica humana (Vigotski, 1995, p.132); a maturação, portanto, compreendida como maturação biológica, não nos ajuda a compreender e a explicar o desenvolvimento humano. Para o autor, a gênese das funções psicológicas superiores é o que interessa à psicologia humana.

Nesse sentido, Bernardes e Asbahr analisaram o desenvolvimento de algumas das funções psicológicas superiores, a unidade interfuncional entre essas funções e o papel da educação escolar no desenvolvimento psicológico. Os autores explicitam, também, essa passagem da primazia das funções biológicas para as funções culturais, exemplificando com o desenvolvimento de uma das funções psicológicas superiores, a memória:

Luria, ao referir-se ao processo de transformação no uso da memória, afirma que "(...) o desenvolvimento subseqüente não significa melhora da memória natural, mas sim, substituição: substituição de métodos primitivos por outros, mais eficientes, que aparecem no processo da evolução histórica" (grifo do autor). Refere-se também, nesse sentido, ao uso, por parte da criança, de objetos externos como instrumentos mediadores para controlar o processo interno da memória. Conforme a criança se insere no processo de escolarização, faz uso de novas técnicas, como a anotação, as quais suprem os procedimentos anteriores. O uso de novas técnicas é considerado pelo autor como um processo de reequipamento da memória por meios alternativos, culturais (Bernardes \& Asbahr, 2007, pp. 325-326)

Segundo os pressupostos da teoria históricocultural, a transformação da memória, bem como das demais funções psicológicas superiores, não pode ser entendida como simples maturação estrutural, mas sim, como metamorfose cultural decorrente do processo de reequipamento cultural possibilitado pelo conteúdo das relações interpessoais apropriadas pelos indivíduos. A transformação da memória relaciona-se intimamente com a transformação das outras funções psicológicas superiores, dando ao desenvolvimento psicológico uma dimensão muito mais cultural do que natural.

Nesse sentido, deve-se ressaltar que o desenvolvimento das funções psicológicas superiores ocorre a partir de mediações culturais. Tal compreensão desloca o foco das dificuldades da aprendizagem do nível individual para o social, e coloca o problema da qualidade das mediações culturais 
presentes na vida da criança (Facci, Eidt, \& Tuleski, 2006).

\begin{abstract}
Verifica-se que as causas do atraso mental não podem ser explicadas somente a partir de anamneses, entrevistas e testagens psicométricas, ou seja, com instrumentos que buscam as causas do não aprender na criança e em sua família, mas essa análise deve ser ampliada para a atividade de ensino e de aprendizagem, especialmente no que se refere à qualidade do conteúdo ministrado, à relação professor-aluno, à metodologia de ensino, à adequação de currículo, ao sistema de avaliação adotado, em suma, ao acesso da criança ao mundo dos instrumentos e signos culturais (2006, p. 111)
\end{abstract}

A mediação pedagógica vem sendo assumida cada vez mais como uma categoria central na atividade educativa nas mais diferentes perspectivas teóricas. Nesse processo de adoção da referida categoria, é comum ouvirmos a defesa, ampla e hegemonicamente aceita, de que os professores são os mediadores da aprendizagem. Além disso, o papel de mediador aparece nessas defesas, também, como sinônimo de um facilitador da aprendizagem.

Haveria algum problema em assumirmos essa defesa? Não é correto que o professor deve ser um mediador na sala de aula e deve facilitar o trabalho dos educandos?

\footnotetext{
Ora, quando se pensa na mediação fundada na dialética, deve-se considerar que ela requer a superação do imediato no mediato. Assim, é provável que o educador 'dificulte' a aprendizagem do educando, pois o educador precisa fazer com que o educando supere a compreensão imediata assumindo outra que seja mediata (Almeida, 2002, p.8)
}

Desse modo, o educador jamais pode ser o mediador do processo de ensino e aprendizagem, tampouco o facilitador, posto que ele mesmo é um dos polos da relação a ser mediada: professor-aluno, ensino-aprendizagem, mediato-imediato. O educador, portanto, é sujeito do processo de ensino e de aprendizagem, sujeito que organiza a atividade de ensino, esta sim, assumindo o papel de mediação entre os dois polos da relação, ou seja, buscando estabelecer a relação entre o imediato (os conhecimentos empíricos que os educandos trazem de suas vidas) e o mediato (os conhecimentos teóricos que o professor quer ensinar para os estudantes).

Diante dessas argumentações sobre a mediação, devemos considerar que se, por um lado, não basta esperar que as crianças se desenvolvam culturalmente, por outro lado, também não basta organizar o seu desenvolvimento. Especialmente na escola, é preciso organizar de um determinado modo esse desenvolvimento, modo esse que permita às crianças se apropriarem das máximas possibilidades mediadas de relação do homem com o mundo que foram sendo criadas. Por isso, valorizar as experiências cotidianas dos educandos como estratégia pedagógica mediadora para a organização do ensino (e, em consequência, para o desenvolvimento dos sujeitos) significa uma hipervalorização dessas experiências (que já são abundantes nas vidas cotidianas dos estudantes) e um abandono, dessa vez por outras vias, do processo de desenvolvimento cultural dos sujeitos em suas máximas possibilidades.

\section{Considerações finais}

$\mathrm{Na}$ perspectiva teórica assumida neste trabalho, a escola tem papel central no desenvolvimento de seus estudantes, na medida em que cria condições para que se apropriem -através de mediações culturais planejadas e intencionais - dos conhecimentos acumulados pela humanidade, conhecimentos esses que encarnam as novas possibilidades de conduta das crianças, como a atenção voluntária, a memória lógica, o pensamento teórico, a capacidade de leitura e escrita, etc. Essas funções ou condutas estão presentes para cada indivíduo apenas como uma potencialidade, e estão presentes externamente aos indivíduos, isto é, sob a forma de objetos e de relações externas. 
Nesse sentido, esperar o desenvolvimento das crianças, esperar que elas em algum momento alcancem determinadas novas funções significa, na maioria das vezes, contentar-se com o não desenvolvimento da criança.

A solução parece estar, então, em proporcionar condições ótimas de relações das crianças com aqueles objetos culturais. Entretanto, essa estratégia pode resultar, na prática pedagógica, no mesmo abandono do processo de desenvolvimento da criança, pois, como já afirmado, para desenvolver-se culturalmente, "a criança, o ser humano, deve entrar em relação com os fenômenos do mundo circundante através de outros homens, isto é, em um processo de comunicação com eles" (Leontiev, 1978, p. 290), e é a qualidade dessa comunicação com os outros que pode determinar de modo mais direto a qualidade do desenvolvimento da criança.

Nesse sentido, cabe à educação escolar ampliar o desenvolvimento do estudante, ou seja, a escola, a partir da organização adequada do ensino, pode produzir desenvolvimento. Assim, os conteúdos escolares devem ser organizados de maneira a formar na criança aquilo que ainda não está formado, elevando-a a níveis superiores de desenvolvimento. Cabe ao ensino orientado produzir na criança neoformações psíquicas, isto é, produzir novas necessidades e motivos que irão paulatinamente modificando a atividade principal dos alunos e reestruturando os processos psíquicos particulares (Davidov, 1988).

Tal concepção de desenvolvimento reconfigura o papel da maturação no processo de aprendizagem e dá à educação escolar um papel central no desenvolvimento das funções psicológicas superiores. Em um sentido oposto ao que vemos nas teorias maturacionistas, não cabe à escola esperar que a criança amadureça. Ao contrário, é seu dever criar condições para que a maturação se efetive. 


\section{Flávia da Silva Ferreira Asbahr}

Doutora em Psicologia pelo Instituto de Psicologia da Universidade de São Paulo e docente da Universidade Estadual Paulista Júlio de Mesquita Filho (UNESP), Bauru - SP - Brasil.

E-mail: flaviasfa@yahoo.com.br

\section{Carolina Picchetti Nascimento}

Doutoranda em Educação pela Universidade de São Paulo, São Paulo - SP - Brasil.

E-mail: carolina_picchetti@hotmail.com

\section{Endereço para envio de correspondência:}

Departamento de Psicologia/ Faculdade de Ciências Universidade Estadual Paulista Júlio de Mesquita Filho. Avenida Engenheiro Luiz Edmundo Carrijo Coube, no 14-01, Vargem Limpa. CEP: 17033-360. Bauru, SP

Recebido 05/05/2011, 1aㅡ Reformulação 01/10/2012, Aprovado 22/01/2013. 


\section{Referências}

Almeida, J. L. V. (2002). A mediação como fundamento da didática. In Anais da 25a Reunião da ANPED - GT 04. Caxambu, MG. Recuperado em 11 março, 2005 de http://www.anped.org.br.

Asbahr, F. S. F., \& Lopes, J. S. (2006). A culpa é sua. Psicologia USP, 17, 53-73.

Bernardes, M. E. M., \& Asbahr, F. S. F. (2007). Atividade pedagógica e o desenvolvimento das funções psicológicas superiores. Revista Perspectiva, 25(2), 315-342.

Carvalho, J. S. F. (1999). De psicologismos, pedagogismos e educação (pp. 111-122). São Paulo: International Studies on Law and Education.

Chaiklin, S. (2011). A zona de desenvolvimento próximo na análise de Vigotski sobre aprendizagem e ensino. Psicologia em Estudo, 16(4), 659-675.

Davidov, V. V. (1988). La enseñanza escolar y el desarrollo psíquico: investigación psicológica teórica y experimental. Moscu: Progresso.

Facci, M. G. D. (2004). A periodização do desenvolvimento psicológico individual na perspectiva de Leontiev, Elkonin e Vigostski. Cad. CEDES, 24(62), 64-81.

Facci, M. G., Eidt, N. M., \& Tuleski, S. C. (2006). Contribuições da teoria histórico-cultural para o processo de avaliação psicoeducacional. Psicologia USP, 17, 99-124.

Ilyenkov, E. V. (2008). The dialectics of the abstract and the concrete in Marx's Capital. Delhi: AAKAR Books.

Heller, A. (1991). Sociologia de la vida cotidiana. Barcelona: Península.

Heller, A. (2000). O cotidiano e a história (6a ed.). Rio de Janeiro: Paz e Terra.

Kosik, K. (2002). Dialética do concreto. São Paulo: Paz e Terra.
Leontiev, A. (1978). O desenvolvimento do psiquismo. Lisboa: Horizonte Universitário.

Leontiev, A. (1983). Actividad, conciencia e personalidad. Havana: Editorial Pueblo y Educación.

Makarenko, A. (1980). Poemas pedagógicos. Lisboa: Livros Horizonte.

Marx, K. (1989). O método da economia política. In F. Fernandes (Org.). Marx e Engels: história (pp. 409-417). São Paulo: Ed. Ática. (Coleção Grandes Cientistas Sociais).

Pasqualini, J. C. (2009). A perspectiva histórico-dialética da periodização do desenvolvimento infantil. Psicologia em Estudo, 14(1), 31-40.

Teixeira, E. S. (2003). A questão da periodização do desenvolvimento psicológico em Wallon e em Vigotski: alguns aspectos de duas teorias. Educação e Pesquisa, 29(2), $235-248$.

Vigotskii, L. S. (1988). Aprendizagem e desenvolvimento intelectual na idade escolar. In L. S. Vigotskii, A. R. Luria \& A. N. Leontiev. Linguagem, desenvolvimento e aprendizagem (5a ed., pp.103-117). São Paulo: Ed. Ícone.

Vygotski, L. S. (1995). Obras escogidas (Vol. 3). Madrid: Machado Libros.

Vygotsky, L. S. (1930). A transformação socialista do homem. URSS: Varnitso. Recuperado em 22 abril, 2009, de Marxists internet archive: http//:www.marxists.org/.

Vygotsky, L. S., \& Luria, A. R. (1996). Estudos sobre a história do comportamento: símios, homem primitivo e criança. Porto Alegre: Artes Médicas. 